\title{
Analysis of Provision of Education Infrastructure and Its Challenges in Ethiopia, The Case of Gimbi Town Primary Schools (Oromia Region)
}

\author{
Desalegn Fekadu Etefa, PhD Candidate \\ Ambo University: Institute of Cooperatives and Development Studies, Department of Cooperative
}

\begin{abstract}
Education is one of the most infrastructures, which is a prerequisite to the socio-economic and environmental development of a country. The objective of this study was to examine the status of the provision of quality education, identify problems hindering its provision and ultimately to suggest some intervening strategies to improve its provision. The study was conducted to meet the stated objectives and hence to do so, 125 teachers' respondents were randomly selected to provide detail information. Moreover, 30 individuals whose day to day activities are related to education were purposively selected to provide further information. In short, 155 respondents were selected, which were expected to provide information relevant to the intended objective of the study. Moreover, the existing educational infrastructure, the styles of services provided and existing facilities in Gimbi town were observed. The result of the study reveals the existing demand is not proportional to the expected educational services and facilities. There is shortage of adequate schools, classrooms, instructional materials, teaching aids, well qualified and committed teachers and financial resources that limited access and coverage of the primary schools. Weak institutional capacity, population growth due to rapid urbanization, low stakeholders' participation, lack of motivation particularly of teachers and directors, lack of skilled manpower, inadequacy of educational facilities and above all lack of financial resources contributed a lot for the inadequate provision of educational services in the study area. These problems led to high dropout and repetition rate, poor quality of education and above all, poor academic performance. To improve this conditions, the study has come up with the possibilities of allocating adequate financial resources, constructing additional schools and classrooms in some of the existing primary schools, employing skilled manpower, improving access and the quality of education and involving all stakeholders as partners of the local government so as to improve the coverage and quality of educational services and facilities in Gimbi town primary schools.
\end{abstract}

Keywords: Education, Educational Inputs, Educational Quality, Education Infrastructure, Instructional Materials, Primary Schools, Standard.

DOI: $10.7176 / \mathrm{JEP} / 10-25-01$

Publication date:September $30^{\text {th }} 2019$

\section{Introduction}

Today, the world is experiencing fast population growth leading to urban expansion. As urbanization increases, the demand for infrastructure also increases, which in turn requires huge investments. It is obvious that providing adequate and effective public services to these growing urban centers is very crucial to the demands of citizens. Thus, to ensure sustainable development, accesses to basic public services are claimed to be vital requirements (Desalegn, 2012).

Unfortunately, developing countries are not in a position to provide these basic infrastructural facilities to their growing population mainly of cities and urban centers. Due to this, cities and urban centers existing in such conditions are suffering from an inadequate service delivery. This diminishes the quality of life as consumers receive unreliable and poor services, which predominantly affects the poor who have the fewest options and least likely to obtain alternative services (Ministry of Urban Works \& Development, 2006).

Of the basic infrastructure, educational infrastructure is the most necessary one, which is a prerequisite to the socio-economic and environmental development of a country. With this regard, despite many trials have been made to make more schools in SSA countries; the provision of educational service is yet not developed than the other parts of the world. Consequently, the region faces many challenges in meeting the goals of educational facility with an increment of the students' population (Secondary Education Initiative in Africa (SEIA, 2007). That means, schools lack many basic facilities and suffer from overcrowding. Study conducted on the regional overview on SSA by UNESCO indicated, in 2000 , only $58 \%$ of children were enrolled in primary schools, which is the lowest enrollment in relation to any region. There were more than 40 million children, almost half of the school age child population receiving no schooling, where two-third was girls (UNESCO, 2000). This verifies there is a gender gap in terms of enrollment to school.

Ethiopia, as one of the developing countries, is not an exceptional case; experiencing the fast growth of urbanization and rapid population growth. Report on the currently existing urban areas show their population is rapidly increasing. To date, there are 925 urban centers at different growth stages in Ethiopia and their annual 
urban population growth rate is estimated to be above $4.3 \%$ (Desalegn, 2012). Consequently the numbers of locations classified as township in the country are currently increasing and all requiring basic urban services and infrastructure. Of the urban social infrastructure and services, education is one part that its demand is much greater than its supply (World Bank, 2006).

It is clear fact that education is one of the key social services. The knowledge on the wise use of scarce resources can be achieved only through education and training. They are only educated people that can command the skills necessary for sustainable growth and for the better quality of life. This means, all sectors of the economy including industry depend on the education sector for the production of skilled human resources. This indicates a well-developed educational sector transforms the economy to industrialization (Desalegn, 2013).

Furthermore, education provides a fundamental base for all further human development upon which material development can occur. Due to this, extending a basic level of education to all children, young people and adults around the world has captured the imagination of all nations. Besides, it is widely believed that the expansion of educational opportunities is a keystone to the nation's accelerated socio-economic development, and hence, its availability and quality are central to the human resource development of any society. Many writers were arguing that skilled and educated manpower is a determining factor for national development. In connection to this, Derebssa (2008) pointed out that one of the frequently mentioned development bottleneck is lack of skilled manpower. Therefore, it is believed that countries truly worrying of their national development give prior attention for strengthening of their education sector due to the fact that it is a cornerstone of societies and their political, economic and scientific institutions (Olembo, cited in Dereje, 2008).

In Ethiopia, the introduction of modern education accounts more than 100 years. In spite of its old age, small sections of the society were benefited from the system during that period due to the limited number of schools, even in urban centers. It is only after 1991 that the large proportions of society have got access to educational services. Now a day, thousands of schools are constructed in both urban and rural areas of the countries.

Although significant progress has been made by the government in enhancing access and coverage of education to its citizens, its provision is challenged by various inadequacies in both of quality and quantity inputs such as school, classrooms, teaching equipment and facility etc. (MoE, 2004).

Despite good efforts made by the government, the existence of multidimensional problems such as weak institutional capacity, low stakeholder participation and rapid population growth hinder the provision of adequate educational services and facilities by the education sector.

The above listed problems exist in Gimbi town's educational sector, which is one of the towns in West Wellega Zone of the Oromia Regional State. Hence, the objective of the study is to assess the overall conditions of education infrastructure and facilities, to identify major factors which affect the provision of adequate educational services and facilities, to show intervention strategies and suggest the measures that could be adopted in order to fill the gap to improve the existing situation in the town.

\subsection{Description of the Study Area}

Historically Gimbi town was established in 1873, which is one of the towns found in Oromia National Regional State. During the Feudal and the Dergue administrative systems, Gimbi town, was a center of "Gimbi Awuraja or Gimbi Province”. From 1991 onwards, it became the capital of West Wellega Zone. The town is found at a distance of $441 \mathrm{kms}$ from Addis Ababa to the West of Ethiopia along the main road that passes to Assosa and Dambi Dollo towns. Astronomically the town is found in between $9^{0} 10^{\prime} \mathrm{N}$ and $35^{\circ} 50^{\prime} \mathrm{E}$. In relative location, in all directions, the town is bounded by the Gimbi woreda.

The town is one of the second grade reform towns in the region; and sub-divided in to four kebeles for administrative purpose and has a status of local government. The built area of the town is estimated to be 1,200 hectares.

Figure 1-Map of Ethiopia, Oromia Regional State and Gimbi Town

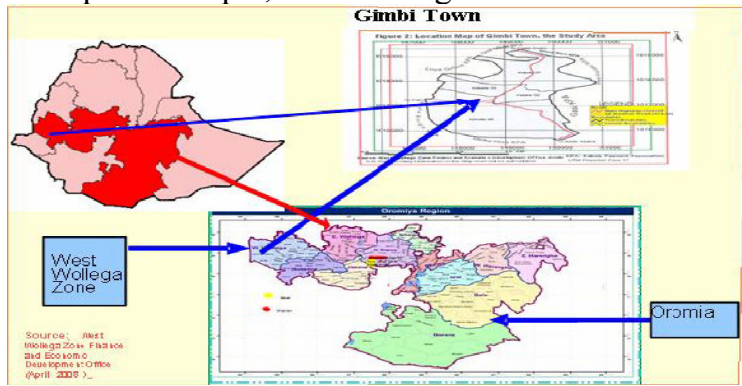

Source: West Wollega Zone Finance and Economic Development Office, 2018

According to the recent estimate, the town's population is above 100,000 . The town has mean annual temperature between $18^{\circ} \mathrm{c}$ and $20^{\circ} \mathrm{c}$, while the annual average rainfall is between 1,600 and 2,277 mm, concerning 
its soil type, most areas in the town have a red clay soil covered with moderately sediment rocks. The town has rugged topography. Urban infrastructure and services, which are important for the socio-economic development, are not adequate in the town, which does not match with the rapid population growth and spatial expansion. For example, all of the existing roads in the town are earth passed with the exception of the main asphalt road and some gravel surfaced road.

\section{Definition and Conceptual Frameworks \\ 2.1 Definition of Terms}

Education: is a process or the result of a process by which an individual acquires knowledge, skills, attitudes and insights. Education includes the development of cognitive (intellectual), affective (attitudes and values) and psychomotor (sensory motor) skills and abilities. It may also be defined as growth, the cumulative effect of changes in behavior resulting from experience, both planned and unplanned. It can be defined as learning acquired through formal and informal process. This would include formally directed learning from a teacher, mentor, priest, or other adult specifically charged with instructional duties and informal acquisition of learning through interaction with family, peer group, and community. Increasingly in modern societies, an informal and unplanned source of education encompasses books, magazines, television, computer networks (MoE, 2006). It is also defined as a process by which man transmits his experience, new findings, and values accumulated over the years, in his struggle for survival and development through generations.

As a whole, various idealist philosophers and psychologists agree that education is a lifelong process and a universal practice of all societies at all stages of social development geared to the shaping of the individual's personality. In a wider sense, education is composed of formal, non-formal and informal forms, which has its own distinct characteristics.

Primary Education: is defined as general school education at the first level [plus non formal education at this level] programs designed to give skills in innumeracy and literacy and to build the foundations for further learning. As to the Ministry of education (2004), primary education is defined as educational structure having two cycles: the first cycle (grade 1-4) and second cycle (grade5-8), which means an education system consisting of an eight years' primary cycle.

Educational Materials and Facilities: These are furniture and equipment which include a set of special environment, physical structure, space arrangement, text books, teacher guides, computers, maps and other aids. They are important ingredients in the teaching-learning activities that speed up the implementation of the intended curriculum goals and enhance students' achievements (Jeilu, 2007).

Quality Education: Quality in the context of education embodies complex phenomena, however, as to MoE (1994); Derebssa (2001) some of this includes:

L Learners who are healthy, well-nourished and ready to participate and learn, and supported in learning by their families and communities;

- Environments that are healthy, safe, protective and gender-sensitive, and provide adequate resources and facilities;

$\Rightarrow$ Content that is reflected in relevant curricula and materials for the acquisition of basic skills, especially in the areas of literacy, numeracy and skills for life, and knowledge in such areas as gender, health, nutrition, HIV/AIDS prevention and peace;

- Processes through which trained teachers use child-centered teaching approaches in well-managed classrooms and schools and skillful assessment to facilitate learning and reduce disparities; and outcomes that encompass knowledge, skills and attitudes, and are linked to national goals for education and positive participation in society. 


\subsection{Conceptual Framework of the Research Problem}

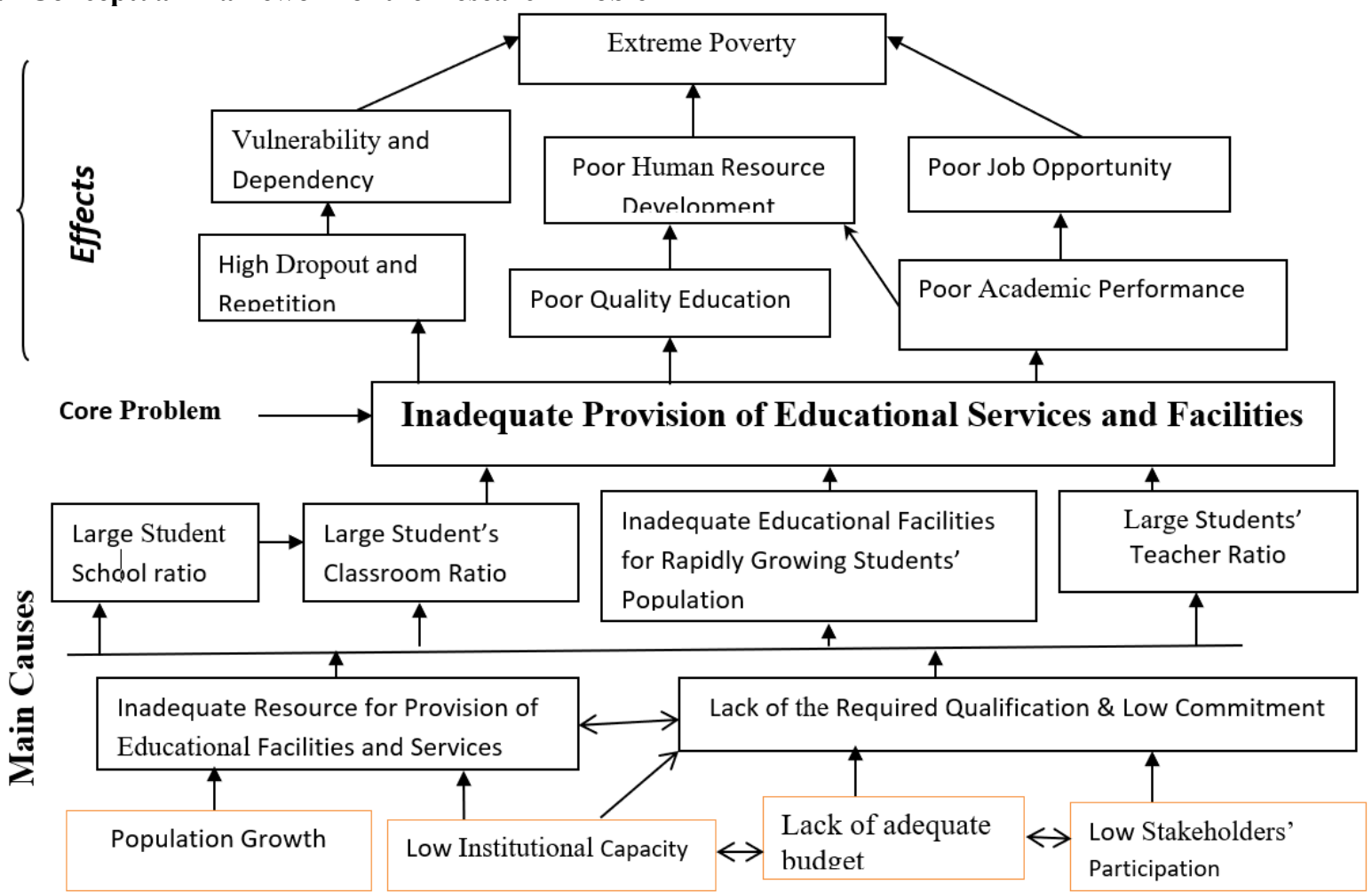

Source: Writer, 2018

\subsection{The Role of Education}

Many development scholars and development advocates stress that no country has secured socio-economic development without a sound educational system. The finding of Fullon (1991) justified that the centrality of education as a core and principal engine for development and nation is unquestionable. In the same way, Tadaro (1985) and Hallok (1990) underlined that it is not the human resources of a nation, not its capital or its material resources that eventually determine the character and place of its economic and social development. These human resources need to be trained, educated and developed for a country to realize its development objectives.

It is a basis for developing capacity to cope with the readily evolving and changing society in an information age. Therefore, its universal availability and quality are central to the development of human resource of any society. A well-educated community member is a determined yet humble participant, who helps overcome conflict and division thereby contributing to a spirit of unity and collaboration. This implies without education, development will not occur as it is only an educated person that can command the skills necessary for sustainable economic growth and for a better quality of life (UNICEF, 2000; Derebssa, 2008).

Investing in education has great role in producing productive citizens. Research reveals that at the individual level, children who are educated have better opportunities for higher incomes in adult life, deceased poverty, reduced criminal activity, greater political participation, better health, and increased life expectancy. Moreover, at the national level, when children are educated, their human capital renders development benefits such as lower fertility rates, a greater pool of skilled workers, increased economic growth, and lower dependence on social support programs later in life. The benefits that a country derives from a more educated population also include increased wealth and stability (World Bank, 2006).

It is widely recognized that poverty and illiteracy are intrinsically interrelated, and that education is one of the most efficient ways to empower the poor. Thus, primary education is a powerful lever for poverty alleviation and social and economic growth (ibid). That is why in the present day, education, particularly achieving universal primary education (UPE) is considered as an instrument to mitigate poverty. That is why achieving universal primary education, promoting gender equality (especially in education and empowering women) is considered as recognized as great issue (UNDP, 2003).

Students in less developed countries are likely to attend unsheltered school or one that is poorly designed and these schools are inadequate in educational materials. On average, they receive only 500 hours of learning time and $1.70 \$$ of non-capital material inputs each year and have a teacher with only ten years of formal education. The learning environment typically has few resources, and classes consist of more than fifty children, many of who are chronically undernourished, parasite ridden and hunger. The job of educating children in developing is 
significantly more difficult than it is in developed countries (Desalegn, 2013).

The quality and availability of learning materials too strongly affect what teachers can do. They play a vital role in translating educational objectives in to practice. They are important ingredients in the teaching-learning activities that speed up the implementation of the intended curriculum goals. These materials and facilities that enhance students' achievement in educational service provision are called furniture and equipment which include a set of special environment, physical structure, space arrangement, text books, teacher guides, computers, maps and other aids (Marlaine, 1994).

As to any other developing countries, the teaching-learning environment in Ethiopian schools is not in a situation to attract children. For example; among Ethiopian schools, only $44.2 \%$ are reported to have water and $22.3 \%$ are reported to have latrines. The number of schools with clinic is 247 and those without clinic are 9,083 where the great majorities are found in Oromia Regional State (MoE, 2006). The availability of the mentioned instructional materials has its own contribution to the effectiveness of the teaching-learning process. i.e., the absence of all these educational materials and facilities would paralyze the activity of the education system and negatively affect the achievement of its objectives (Ingram, 1979 cited in Dereje, 2008).

In addition to the above facts, the delivery of quality education is measured in accordance to the set standards. These standards are qualification of teachers, student to section ratio, student to teacher ratio, student to school ratio and the availability of materials and facilities (MoE, 1994).

The qualifications of teachers play a decisive role in the quality of education and hence, determining pupils' achievement. Therefore, qualified teachers are required at different levels of schools. Regarding this, Aggrawal (2004:290) affirmed that Teachers' quality is a function of teachers' mastery of subject matter, knowledge and use of appropriate teaching skills and acquisition of positive attitude. Thus, a sound program of professional education of teachers is needed for improvement of education.

According to the Ethiopian Ministry of Education, the required qualification of teachers ranges from certificate (TTI) to first degree graduate. The national standard indicates that in case of teaching at the first cycle, TTI graduates are fit, Diploma graduates are required for second cycle (5-8) and bachelor degree (university graduates) as the minimum requirement for teachers in secondary school and should possess adequate pedagogical skills (MoE, 1994).

Even though the standard says so, available data suggests that large proportions of primary school teachers lack adequate academic qualifications, training and mastery of content. At the national level, in 2003/04, 96.5\% of the first cycle primary school (grades 1-4) of the teaching force met the national minimum standard, whereas only $32.1 \%$ of teachers teaching at the second cycle (5-8) meet the specified standard. As regards teachers' mastery of the curriculum, a recent study found out that some primary school teachers do not possessed adequate knowledge on the requirements of the curriculum (Derebssa, 2008).

Student to teacher ratio (STR) is another standard of education which shows the degree of the quality of education. The lower the student-teacher ratio (STR), the higher the opportunity of contact between the teacher and the pupil to check homework and class work as well as provide support to students individually. On the other hand, very low STR may indicate inefficient or underutilization of teacher. In Ethiopia, the standard set for the pupil to teacher ratio is 50 and 40 for primary and secondary respectively (MoE, 2005).

All the above listed materials and human resource require adequate budget. In many developing part of the world such as Ethiopia, government is the main source of financing education; however, the support from the community in cash, kind and labor, the effort of schools to generate income, supports from NGOs contribute in provision of educational infrastructure.

Repetition and dropout are the other factors affecting the delivery quality education. High rates of repetition and dropout lead to inefficiency and wastage of scarce resources. While many countries make high investment in education, investment on its own does not guarantee desirable results. If the benefits of investment in the education sector are to be optimized, wastage would have to be avoided or at least minimized since repetition and dropout manifest educational wastage and internal efficiency in the process of achieving educational objectives (UNESCO, 2006).

According to Pope (1993), repetition is the problem of spending more than one academic year in the same grade studying the same curriculum content. Repetition creates class room crowding and obstruction in promotions and enrollment for new comers. This in turn will have adverse effect on the provision of quality education and promoting universal primary school for all. As a whole, both repetition and dropout are caused by low and declining qualities of education. As many literatures documented, most of the challenges to achieve universal primary education comes from different angles, which could be socio-cultural factors, policy related issues, and school related factors and others (World Bank, 2005).

The other serious problem is the shortage of instructional materials which includes lack of teaching aids that can create child friendly school environment. In addition to this, weak institutional capacity which is attributed by having inadequate trained officials and lack of adequate budget are the other sources of challenges. This reveals that the above mentioned challenges need due attention to mitigate the overriding challenges. Therefore, due 
attention is needed from all stakeholders in order to improve the prevailing situations in addition to what the government is showing its commitment.

\section{The Study Approach}

Mixed research design is used, which involves both the qualitative and quantitative approaches in a single study. As Creswell explained, all methods have limitations and felt that biases inherent in a single method could neutralize or cancel the prejudices of other methods (Creswell, 2006). From different strategic models of mixed approach, the researcher selected descriptive design; collecting and analyzing quantitative data followed by collecting and analyzing qualitative data. With regard to the sources, both primary and secondary data were generated and used as an input for the research.

\subsection{Population, Sample and Sampling Techniques}

Since it was difficult to collect data from the population, sample of the selected respondents were the source of information. Sampling is a process of selecting a portion of the designated population to represent the entire population (Polit and Beck, 2008:339). Hence, the valuable information for the study was gathered from the primary schools' directors and supervisors, teachers, and representatives of the community i.e., members of school (Kebele) educational and training management board, town's education head and experts and finance and economic development office. To conduct a research on the nine primary schools in the town, the researcher used both simple random sampling and purposive sampling techniques. This was explained below in the following manner. The primary schools of the town have 181 teachers. To determine the sample size, the formula given by Yemane (1967): $\mathbf{n}=\mathbf{N} / \mathbf{1}+\mathbf{N}\left(\mathbf{e}^{\mathbf{2}}{ }^{\mathbf{2}}\right.$, where $\mathbf{n}$ represents sample size, $\mathbf{N}$ represents population, and $\mathbf{e}$ is the desired level of precision (0.05) i.e., the likelihood that the answer will fall outside that range (the probability not to represent) was used. Thus, depending on this formula, the sample size was 125. Consequently, the valuable information for the study was gathered from 125 individuals through Crosse-sectional survey in connection to the objective of the thesis. To increase the representation of all the target groups in the sample so that valid, unbiased and reliable information has to be obtained, the researcher randomly selected those included in the sample using systematic random sampling technique, where every respondent is selected using lottery method when rounded sample interval was 1.488 which is approximately 2 . The $1^{\text {st }}$ respondent was chosen randomly by blindly picking one out of two. The picked number was the $1^{\text {st }}$ teacher then it continued every $2^{\text {nd }}$ teacher till the last 125 respondent was drawn. In order to get further information, 9 directors, and 2 supervisors, 9 members of school community representatives from each primary school with the total of 9 respondents, 4 town educational officials and 2 administrative officials of the town were taken to provide vital information. Besides, 2 west Wollega zone education office and 2 representatives of the town teachers' association were the other respondents provided important information. They were selected by using purposive sampling techniques to obtain valuable information. In general, 155 respondents provided necessary data to achieve the purpose of the study.

\subsection{Data Collection Tools}

To gather primary data during the study, the structured questionnaires were prepared in English and translated into Afan Oromo (local language) for the local people to understand the questionnaires and then translated back into English for analysis. The questionnaires were both close and open ended to get information in accordance to the research objectives. These data have been collected mainly by distributing questionnaires that contain both close and open ended questions. There were three sets of questionnaires mainly for school heads (school directors), primary school teachers and representatives of the community or parents.

Since it provides richer information while collecting data, interviews viz. through face to face conversation were also used. Accordingly, structured and semi-structured interview questions were prepared to collect data. The structured interview was framed to all respondents namely the town administrative officials, educational officials, representatives of the community, and directors of all the primary schools those intended to provide valuable information on the provision of educational services and facilities of the Gimbi town primary schools.

Furthermore, during his stay in the field, the researcher tried to systematically observe realities on the ground to get primary information on the stated issues and to take sample photographs during site observation to describe and give more visualization on the existing situation. As the photographs are more expressing than raw data, and give more insights toward what the study area looks like, it was also used. To do this, the researcher prepared and used checklist to verify items of the existing situation of educational infrastructural services and facilities of the town.

\subsection{Data Analysis and Presentation}

The data collected were carefully tallied. To make the data workable for the analysis, data were processed by editing, coding, classification and tabulation. In general, data were analyzed by descriptive statistics. These data were presented by using tabular and graphic form where necessary. Ultimately, both the qualitative and 
quantitative data were appropriately interpreted in the way they give meaningful sense for the readers. The qualitative data were interpreted by words particularly using coding, narrative and content analysis techniques. The quantitative data on the other hand were interpreted numerically by frequencies, percentages and averages.

\section{Results, Interpretation and Discussion}

\subsection{General Background of the Respondents}

\subsubsection{Sample Teachers' Qualifications and Experiences}

Primary Schools' Teachers are one of the sampled respondents for this study. These respondents were asked about their sex, educational qualification and service year (experience). The study, therefore, begins by treating these characteristics that is presented and analyzed as follows.

Table 4.1: Sex and Educational Qualification of the Sample Teachers' Respondents

\begin{tabular}{lll}
\hline Qualifications & Sex of Respondents & Percentage of Respondents \\
\hline Certificate(TTI) & M 30, F 19 & M 24\%, F 15.2\% \\
Diploma(TTC) & M 24, F 46 & M 19.2\%, F 36.8\% \\
Degree & M 4, F 2 & M 3.2\%, F 1.6\% \\
Total & M 58, F 67 & M 46.4\%, F 53.6\% \\
\hline
\end{tabular}

Source: Survey, 2018

As can be seen from Table 4.1, 67 (53.6\%) of the sampled teachers are females whereas $58(46.4 \%)$ of them are males. With regard to respondents' educational qualification, it is notable that $49(39.2 \%)$ of the respondents are graduates of teachers' training institute (TTI) and about $70(56 \%)$ of the total respondents' educational qualification is diploma i.e., from teachers' training colleges (TTC) whereas the rest $6(4.8 \%)$ of them are degree holders. This implies more than half of them fulfill the required qualification to teach second cycle primary schools i.e., 5-8 grade.

Table 4.2: Service Year and Sex of the Sampled Teachers

\begin{tabular}{lllllll}
\hline Service Year & Male & \multicolumn{3}{c}{ Female } & \multicolumn{3}{c}{ Total } \\
& No. & $\%$ & No. & $\%$ & No. & $\%$ \\
\hline 1-5 years & 3 & 2.4 & 4 & 3.2 & 7 & 5.6 \\
6-10 years & 5 & 4.0 & 2 & 1.6 & 7 & 5.6 \\
11-15 years & 22 & 17.6 & 8 & 6.4 & 30 & 24.0 \\
16 years and above & 28 & 22.4 & 53 & 42.4 & 81 & 64.8 \\
Total & 58 & 46.4 & 67 & 53.6 & 125 & 100 \\
\hline
\end{tabular}

Source: Field Survey, 2018

As far as respondents' service year is concerned, majority have enough working experience in the fields of their profession as indicated in Table 4.2. As it is shown here, about $81(64.8 \%)$ of them have 16 years and above and $30(24 \%)$ of them have service year that ranges between 11-15 years while the rest $14(11.2 \%)$ of the respondents have a service year that ranges from 1-10 years in the fields of teaching.

\subsubsection{General Background of the Primary Schools' Directors in Gimbi Town Administration}

In addition to the general background of the primary schools' teachers who are included in the sample, background of the directors is also considered in the study. As the information obtained from the directors indicate, majority of them fulfill the minimum criterion. For this investigation, the reply of the respondents reveals that $3(33.33 \%)$ are first degree holders and $5(55.56 \%)$ of the respondents have diploma in their educational qualification while only about $1(11.11 \%)$ of the respondent is graduate from teachers training institute (TTI). This means majority of the directors are qualified, which implies their fitness to the minimum requirement of the profession.

Concerning their experience, 3 (33.33\%), $4(44.44 \%)$ and $2(22.22 \%)$ have work experience in leadership position for 7-10 years, 3-6 years and 1-2 years respectively and as a general, 7 (77.78\%) have working experience greater than 3 years which is also a minimum requirement to be school director. This shows most of the primary school directors of the town have fulfilled the minimum standard set by the ministry of education.

4.1.3 General Background of the School Parent Teachers' Association or Kebele Education and Training Management Board Respondents

Community participation in education provision is one of the very crucial elements. When people participate directly or through their representatives in defining visions for sustainable development for their own, in formulating strategies for equitable access to services and resources and in setting priorities for action, they readily commit to support the activities they have endorsed. All stakeholders should be able to influence plans for services directly, involve in monitoring and evaluation and suggest ways of improving them. Taking this into account, Ethiopian Ministry of Education (MoE) formulated strategy to involve community as one of the stakeholders in the education system. One way of community involvement is taking part either through their representatives or direct involvement of the community in their issues. Therefore, in this way, the local government entails community in the school's activity through parent teacher association (PTA) and kebele education and training 
management board (ETMB) members at school level. In line with this, to perceive their roles in the primary schools of the town, analysis begins with elucidating their background.

In line to this, data collected reveals that the majority $6(66 \%)$ of the primary schools' PTA and kebele ETMB members are males and about $3(33 \%)$ of them are females. At the same time, their educational level was also included for the analysis. In connection to this, the data collected shows $2(22 \%), 2(22 \%), 1(11 \%), 1(11 \%)$ and $3(33 \%)$ of the PTA and ETMB members have attended grade 1-4, 5-8, 9-10, 11-12 and above grade 12 respectively. Regarding the work experience of the schools' PTA and kebele ETMB members, $6(66 \%)$ of them have service year that ranges from 1-6 whereas, the rest 3 (33\% have an experience of above 6 years.

\subsection{Demands for Education and its Coverage in Gimbi Town}

Now a day, the government of Ethiopia is paying great attention to have a qualified human power. This can be confirmed by the fact that the government is keen to improve access to education by all as per i.e., to achieve universal primary education for all. Despite this, a significant portion of school going age is not enrolled in school. In line to this, the information obtained from Gimbi town education office indicates that in the year 2017, there were about 16,067 primary school age populations in the town's administrative boundary. Out of these, students registered to the schools are $14,256(88.73 \%)$. The rest $1,811(11.27 \%)$ primary school age populations are not joined up the school. This in turn causes a problem in achieving the target i.e., Primary education for all.

4.2.1 Trends of Primary School Age Population, School Age Enrollment and Participation Rate of Gimbi Town

Table 4.3: Primary School Age Population of Gimbi Town Administration, 2013-2017

\begin{tabular}{|c|c|c|c|c|c|c|c|c|c|}
\hline \multirow[t]{2}{*}{ Year } & \multicolumn{3}{|c|}{ School Age Population } & \multicolumn{3}{|c|}{ School Age Enrollment } & \multicolumn{3}{|c|}{ Participation Rate } \\
\hline & M & $\mathrm{F}$ & $\mathrm{T}$ & M & $\mathrm{F}$ & $\mathrm{T}$ & M & $\mathrm{F}$ & $\mathrm{T}$ \\
\hline 2013 & 5,784 & 4,981 & 10,765 & 5,096 & 3,983 & 9,079 & 88.11 & 79.96 & 84.34 \\
\hline 2014 & 6,847 & 5,731 & 12,578 & 5,975 & 4,683 & 10,658 & 87.26 & 81.71 & 84.74 \\
\hline 2015 & 7,548 & 6,308 & 13,856 & 6,474 & 5,293 & 11,767 & 85.77 & 83.91 & 84.92 \\
\hline 2016 & 8,174 & 7,584 & 15,758 & 6,947 & 6,482 & 13,429 & 84.99 & 85.47 & 85.22 \\
\hline 2017 & 8,103 & 7,964 & 16,067 & 7,290 & 6,966 & 14,256 & 89.97 & 87.47 & 88.73 \\
\hline
\end{tabular}

Source: Gimbi Town Administration Education Office, 2018

As it is observed from Table 4.3, there is a wide gap between the school age population and students enrolled to the schools. This implies all of the primary school age populations of Gimbi town administration are not enrolled. As of the year 2017, of the 16,067 school age population, those who entered to school were 14,256 with a difference being 1,811 students who fail to go to school. As information obtained from the schools' PTA and kebele ETMB members revealed some of the low income families lack interest to send their children at their mature age. Majority of them allow their children to enter $1^{\text {st }}$ grade level at the later age. The other reason identified is due to the topography of the town; for fear their children could not travel the ups-downs of the terrain, the families lack willing to send their children at an early age. On the other hand, there are also families who complain the current employment opportunities of those graduated from TVET, different colleges and Universities, supporting a saying of those people who advocate the current educational policy is making pupils jobless. As a whole, due to both the collective effects, there is mismatch between the school age population and students enrolled to schools in the town.

\subsection{General Background of the Primary Schools in Gimbi Town}

In Gimbi town administration, in the year 2017, there are nine primary schools namely: Malka Bidiru, Biftu Gimbi, Madanalam, Kaso, Adventist, Badesa Mako, Burka Gimbi, ManaSiressa and Burkitu Gafare primary schools. There are also two private schools that are on the process by the time this research was undertaken.

\subsubsection{Primary Schools by Ownership}

Government alone cannot satisfy all the public services. Now a day, in most countries of the world, these growing public demands are provided at large by promoting the private sectors to participate in financing, implementing and managing infrastructure services. On the contrary, in the town administration, as confirmed from study, almost all the educational infrastructure and services are provided by single source. As an interview conducted with the town education officials demonstrate, of the nine (9) primary schools functioning in the town, only one of them is religious based organization (RBO). This shows there is no private sector, NGOs and community based organizations involvement on education investment in the town administration. From this, it could be inferred that this is one of the impediment factors to meet the growing demand in the study area.

\subsubsection{Accessibility and Shifting System of the Primary Schools}

With regard to the accessibility of the site of the schools, some of the primary school's directors, 3 (33.33\%) respondents said that the primary schools are accessible while $2(22.22 \%)$ of them supposed the primary schools in the town is partially accessible and the rest 4 (44.44) \% of the directors replied that inaccessible. Four of the 
directors who disagree with the accessibility of the primary schools rationalized their view. As to them, the topography of the town is characterized by ups and downs which is difficult particularly for $1^{\text {st }}$ grade children to cross the rugged terrain, which is also factual.

The research conducted by Miske and Dowd (1998) confirmed that when schools do not have adequate infrastructure, parents may be reluctant to allow children especially girls to attend if they are located too far away from children's homes. In general, parents often consider the location and condition of learning environments when assessing school quality and this can influence school participation. In support of this view, the existing primary schools are not accessible for all school age population of the town. The other area of the school background is whether the existing primary schools are using shifting system. Accordingly, 7 (77.78\%) of directors confirmed that the primary schools use shifting system while $2(22.22 \%)$ of directors agreed that they are not using shifting system and the number of shifts per day for those who use is two. Despite this, most of the primary schools' classrooms a time (one shift) are still accommodating large numbers of students beyond the required standard set by the Ministry of education.

Table 4.5: Accessibility and Shifting Systems

Issues Regarding Accessibility of Schools and Shifting Systems No.

$\%$

$\begin{array}{lll}\text { A. Accessible } & 3 & 33.33 \\ \text { B. Partially accessible } & 2 & 22.22 \\ \text { C. Not accessible } & 4 & 44.44 \\ \text { Number of shifts } & - & - \\ \text { A. Two } & 7 & 77.78 \\ \text { B. No shift } & 2 & 22.22 \\ \text { C. Three } & - & -\end{array}$

Source: Field Survey, 2018

\subsection{Trends of Enrollment, Dropout, Repetition and Promotion of Primary School in Gimbi Town}

This trend of enrollment is different from trends of participation of school age population which was discussed in the previous section because it includes both the primary school age population (age 7-14) and that of population who are enrolled in the school age being out of school age population i.e. including less than 7 and greater than 14 ages. In line with the trend of enrollment, dropout, repetition and promotion of the primary schools of the town, the gathered data from the respondents was analyzed as follows.

Table 4.5: Trends of Enrollment, Dropout, Repetition, and Promotion of Primary Schools

\begin{tabular}{llllllllllllll}
\hline Year & \multicolumn{2}{c}{ Enrollment } & \multicolumn{4}{c}{ Dropout } & \multicolumn{4}{c}{ Repetition } & \multicolumn{3}{c}{ Promotion } \\
& $\mathrm{M}$ & $\mathrm{F}$ & $\mathrm{T}$ & $\mathrm{M}$ & $\mathrm{F}$ & $\mathrm{T}$ & $\mathrm{M}$ & $\mathrm{F}$ & $\mathrm{T}$ & $\mathrm{M}$ & $\mathrm{F}$ & $\mathrm{T}$ \\
\hline 2013 & 4,381 & 4,471 & 8,852 & 380 & 382 & 762 & 254 & 380 & 634 & 3,747 & 3,709 & 7,456 \\
2014 & 5,096 & 3,983 & 9,079 & 362 & 416 & 778 & 350 & 261 & 611 & 4,384 & 3,306 & 7,690 \\
2015 & 5,975 & 4,683 & 10,658 & 385 & 442 & 827 & 315 & 391 & 706 & 5,275 & 3,850 & 9,125 \\
2016 & 6,474 & 5,293 & 11,767 & 378 & 460 & 838 & 314 & 456 & 770 & 5,782 & 4,377 & 10,159 \\
2017 & 7,290 & 6,966 & 14,256 & 401 & 486 & 887 & 326 & 425 & 751 & 6,647 & 5,971 & 12,618 \\
\hline
\end{tabular}

Source: Compiled from the Town Primary Schools, 2018

As indicated in Table 4.5, the trend of enrollment of students is increasing from time to time in the last five consecutive periods. There was an addition of 4,577 students' enrollment when we compare with the base year i.e., it was 8,852 in 2013 and 14,256 in the year 2017. This indicates students' registered is rapidly increasing in the primary schools of the town. Contrary to this, the number of teachers and classrooms did not increase proportionate to it. It signifies the difficulty to achieve balance between service coverage and quality. As primary school enrollment grew rapidly, pupil-teacher ratio and pupil-section ratio have been increasing steadily and exceeding standards set for the level, negatively affecting the quality of education.

Apart from their admission to schools, the rate of dropout is the other critical issue on the delivery of quality education that has to be considered. Dropout rates commonly used to measure the efficiency of education system in every grade level. Accordingly, in the above Table (4.5), one can detect that for the last five consecutive years, there is a significant number of students' dropout. It vividly illustrates as the enrollment increases, the dropout rate also increases. Even, when we consider the two sexes, the dropout rate is high on the side of female students which seek looking for solutions on the stakeholders. In general, high dropout rate significantly affected the efficient utilization of educational resources of Gimbi town for the last five years. In other words, an increase in dropout rate raises resource allocation for the educational sector of the town.

Besides enrollment and dropout, a trend of repetition is also the other issue to be considered. As of dropout, repetition is also one of the factors that adversely affect the quality of education in one way or another. Repetition is the problem of spending more than one academic year in the same grade studying the same curriculum content. 
Repetition creates class room crowding and obstruction in promotions and enrollment for new comers. The trend of repetition rate is serious on female students which require special attention to narrow the gender gap and to implement the slogan of universal primary education for all in general.

As the interview conducted with the head of Gimbi town education office and representatives of teachers' association prove, dropout and repetition are the main problem of the town in general and that of the primary schools in particular. When we look at the students enrolled to school in the year 2017, they were 14,256 and those promoted were 12,618 . The difference of this figure is 1,638 which is the collective effect of dropout and repetition showing that how much it is affecting the success of the intended goal of the town education sector.

Furthermore, the response from the town education office indicates that dropout and repetition are one of the causes for schools to conduct teaching-learning in two shifts and even to take students beyond their carrying capacities. This could be a reason for large number of students to be assigned to classes, which in turn becomes a reason for large student-teacher ratio, student-text ratio and even student-seat ratio. Ultimately, as a result of all these, it is too difficult to deliver quality education for all. The reason for dropout and repetition in the town are: large students to class ratio, poor quality of education, poor economy of their families, low awareness of families on education, low attention of students on education and sometimes teacher's turnover are the major contributing factors for primary school students' dropout and repetition in schools.

Table 4.6: Teacher's Turnover in the Primary Schools of Gimbi Town, 2013-2017

\begin{tabular}{cccc}
\hline Year & \multicolumn{2}{c}{ Turnover in terms of Qualification } \\
& Certificate & Diploma & Degree \\
\hline 2013 & 3 & 5 & 1 \\
2014 & - & 4 & - \\
2015 & 2 & 1 & 2 \\
2016 & - & 6 & 4 \\
2017 & - & 8 & 3 \\
\hline
\end{tabular}

Source: Compiled from each Primary Schools, 2018

As far as teacher's turnover is concerned, they were 39 teachers who changed their work place to other different offices during the stated periods. With regard to their level of education, in the same periods, they were 5 certificate holders, 24 diplomas and 10 degree holders who shifted from their profession. This indicates significant numbers of experienced professionals are leaving schools, which implies students take time to adapt to the new comers or dropout of schools.

\subsection{Comparison of the Existing Conditions in the Primary Schools of Gimbi Town to the Standard Set by the Ministry of Education}

Standards in educational service provisions are necessary inputs, which indicate the quality of service provision and efficient utilization of scarce resources. This standard constitutes matters like school to pupil ratio, class room to pupil's ratio, teacher to students' ratio, teachers' qualification, class-room size, availability of physical facilities of education. Strictly speaking, it clarifies the required quantities and qualities of educational inputs. These standards are indicators of quality educational services provisions. Therefore, existing condition in the town in line with the set standard is presented and analyzed as follows:

Table 4.7: Comparison of Existing Situation in the Primary Schools with the Required Standard

\begin{tabular}{|c|c|c|c|c|c|c|c|}
\hline 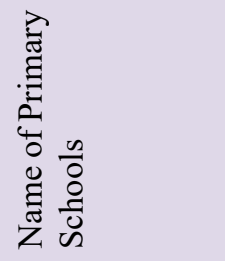 & 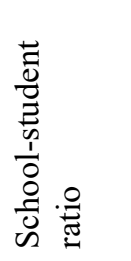 & 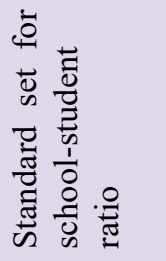 & 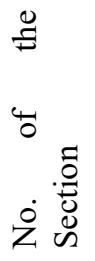 & 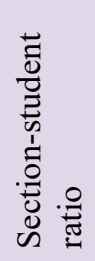 & 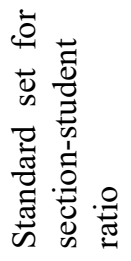 & 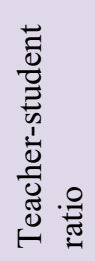 & 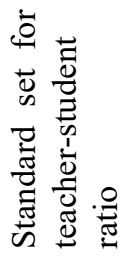 \\
\hline Kaso & $1: 2778$ & $1: 1600$ & 43 & $1: 65$ & $1: 50$ & $1: 68$ & $1: 50$ \\
\hline Malkabidiru & $1: 2397$ & $1: 1600$ & 33 & $1: 73$ & $1: 50$ & $1: 77$ & $1: 50$ \\
\hline Biftu Gimbi & $1: 1781$ & $1: 1600$ & 24 & $1: 74$ & $1: 50$ & $1: 71$ & $1: 50$ \\
\hline Madanalam & 1: 1698 & $1: 1600$ & 19 & $1: 89$ & $1: 50$ & $1: 76$ & $1: 50$ \\
\hline Adventist & $1: 2225$ & $1: 1600$ & 26 & $1: 86$ & $1: 50$ & $1: 98$ & $1: 50$ \\
\hline Badesamako & $1: 1150$ & $1: 1600$ & 16 & $1: 72$ & $1: 50$ & $1: 67$ & $1: 50$ \\
\hline Burka Gimbi & $1: 987$ & $1: 1600$ & 12 & $1: 82$ & $1: 50$ & $1: 70$ & $1: 50$ \\
\hline Mana Siresa & $1: 750$ & $1: 1600$ & 9 & $1: 83$ & $1: 50$ & $1: 83$ & $1: 50$ \\
\hline Burkitu Gafare & $1: 490$ & $1: 1600$ & 6 & $1: 82$ & $1: 50$ & $1: 49$ & $1: 50$ \\
\hline
\end{tabular}

Source: Data Compiled from the Different Primary Schools of Gimbi Town, 2018

The research conducted by Jeilu (2007) shows that the number of schools and classrooms were not in a 
position to accommodate the increasing rate of enrollment. As clearly noticed from Table 4.7, there are maximum numbers of students in Kaso, Malkabidiru, Adventist, Madanalam, and Biftu Gimbi primary schools, where schools' student numbers exceed the maximum standard set by the Ministry of education on school student ratio, by $1,178,797,630,181$ and 98 students respectively. It is quite clear that children retain and learn less when schools are overcrowded, noisy and unsafe. It is only in Badesamako, Burka Gimbi, Burkitu Gafare and Mana Siressa that the schools' students' ratio is below the standard but these four schools have limitations in other standards. That means, these primary schools are serving below the standard set. In general, there is unfair distribution of students in the primary schools of Gimbi town. This can lead to over crowdedness of the schools by the students since they are accommodating beyond their carrying capacities in the case of the above five primary schools. This situation demands the construction of additional classes in the existing schools and also construction of new primary schools in different parts of the town. In case of Badesamako, Burka Gimbi, Mana Siressa and Burkitu Gafare primary schools, there is low school-student ratio but high numbers of students assigned to sections, due to the fact that these four primary schools have few sections.

Data were collected from sample schools on a number of students, teachers and classrooms in each primary school to assess the situation by considering two quality indicators-pupil section ratio and pupil-teacher ratio. Accordingly, from Table 4.7, it is also possible to witness about the existing section student ratio among the primary schools. In line to this, the existing teacher students ratio is $1: 89,1: 85,1: 83,1: 82,1: 82,1: 74,1: 72,1: 71$ and 1:64 at Madanalam, Adventist, Manasiressa, Burka Gimbi and Burkitu Gafare, Biftu Gimbi, Malkabidiru, Badesamako and Kaso primary schools respectively. It is only in Kaso primary school where section-student ratio is relatively nearer to the standard set. From this, one can realize that there is a gap between the existing sections and the primary schools to match with the existing numbers of students in all the primary schools of the town. Therefore, here again, the existing condition itself demands construction of additional classrooms in the existing school to assure the delivery of quality education.

One can also observe teacher's distribution among all the primary schools in Gimbi town as viewed in Table 4.7 above. As of the year 2017, there were about 16,067 school age children in the town though they are 14,256 students registered to schools. On the other hand, in the primary schools of the town, there are 186 primary school teachers who are directly taking part in the teaching-learning process. A student to teacher ratio (STR) is another standard of education. The lower the student-teacher ratio (STR), the higher the opportunity of contact between the teacher and the pupil to check homework and class work as well as provide support to students individually. However, the condition is the reverse in Gimbi town primary schools. It is also indicated in Table 4.7 that teacherpupil ratio is 1:98, 1:83, 1:77, 1:76, 1:71, 1:70, 1:68, 1:67 and 1:49 in Adventist, Mana Siressa, Malkabidiru, Madanalam, Biftu Gimbi, Burka Gimbi, Malkabidiru, Kaso, Badesamako and Burkitu Gafare primary schools respectively. This signifies the entire primary schools are very far from the standard with the exception of Burkitu Gafare which is almost fulfilling the requirement in terms of teacher-pupil ratio. As a whole, the gross ratio of teacher to student is about 1 to 77. However, it varies from school to school and it exceeds by far the average in some sections. This condition is becoming an obstacle to implement the modern teaching methodology which is called "student centered teaching approach" of educational policy. Thus, to ensure the implementation of the quality educational package, employing a minimum of about 10 additional teachers in each primary schools of the town is mandatory.

\subsection{The Town Primary Schools' Teachers Qualification and Experience}

To maintain the quality of education, producing qualified teachers is among the most essential requirement in the education systems. In case of lower primary schools (grade 1-4), the national norms allows graduates from TTI (teachers' training institute) and diploma graduates for upper primary schools (grade 5-8) (MoE, 2005). In connection to this, to prove the existing condition in each primary school at each level of the town, detail information is gathered and presented as follows.

Accordingly, information obtained shows that there are 186 primary schools teachers in the town who were teaching 14,256 students in the year 2017. Concerning their sex, of these teachers, 85 (45.69\%) of them are males while $101(54.3 \%)$ of them are females. This shows majority of them are females. With regard to their qualification, out of these teachers, $105(37.63 \%)$ of them are graduates from teachers training institute (TTI) and 70 (40.6\%) of them are graduates of teachers' training college (TTC) whereas the rest $11(5.91 \%)$ of them are $1^{\text {st }}$ degree graduates. The data also shows there are 37 teachers who are teaching the second cycle (5-8) grade levels who are from the teachers' training institute (TTI) below their qualification violating the standard set. On the other hand, there are also about 9 diploma teachers and $111^{\text {st }}$ degree holders who are teaching below the allowed standard in the primary schools. This shows there is unfair distribution of qualified teachers at different levels in all the primary schools of the town.

In the literature review part, it stated that as large proportions of the primary schools' teachers lack adequate academic qualifications, training and mastery of the content of the subject matter they ought to teach. Similar condition is observed in the town schools. An interview conducted with the town education office indicated the 
rationale behind assigning teachers below the level of the standard set. Accordingly, the reply shows majority of them are poor in academic performance that was also confirmed by the talent students who frequently applied, proofing the above literature. Whereas, some of them have health related problems who got transfer to the town. In short, as regards teachers' mastery of the curriculum, a study found that some of the town's primary schools' teachers do not possess an adequate knowledge on the requirements of the curriculum for the second cycle (5-8 level) primary schools where only $64(34.41 \%)$ of the teachers fit the level. This shows there is a maximum gap between the standard and the existing qualified teachers for the second cycle (5-8) primary schools while there is high concentration of qualified teachers at some schools particularly at the first cycle. From this, it can be deduced that lack of qualified teachers is one of the reasons for poor quality of education that in turn brings about high dropout and repetition rate.

In view of the fact that qualification of teachers play a decisive role in the quality of education and hence, determining pupils' achievement, qualified teachers are indispensable at different levels of schools. To improve the situation, lots of things are expected from the town administration and the concerned sector which requires special attention. In addition to teachers' qualifications, the experience they have in the area of the profession requests further analysis. In line to this, evidence indicated that $22(11.83 \%)$ of them have an experience that ranges from 1-5 years, whereas $134(72 \%)$ are in the ranges of 6-20 years and the rest $30(16.13 \%)$ served above 20 years. This reveals that majority of the town's primary schools' teachers have long service years in the fields of teaching. Anyway, this is not the only requirement, but also the condition of infrastructure, availability of textbooks and learning materials and class sizes demand due consideration to be assessed since they all influence the provision of quality education.

Most of the time, an accumulated long experience is correlated with an accumulated knowledge, which has a great role in the teaching-learning process. Although this is the case, it does not work all the time. For instance, in Gimbi town, some of these teachers are old aged and some have health related problems those who cannot cover the periods to be allocated. As a result of this, some teachers are over loaded and do not have a vacant time from Monday to Friday. In this regard, the sampled primary schools' directors are interviewed concerning the amount of periods each teacher has to cover. Accordingly, the result shows some of them who participate at a single shift teach 36 periods per week and those who serve two shifts cover beyond this. From this one can imagine that in the absence of a single teacher, how much periods of educational time maybe wasted. Apart from this, even if they are present, they are forced to teach without rest, which makes questionable to deliver quality service. In addition, overloaded teachers cannot check student's class work, home work, and different tests and even cannot effectively prepare the contents of the subject in accordance to the syllabus. This case is one of the factors impeding the provision of quality education in the town.

\subsubsection{Employed Teachers by the Town Administration}

Government can play a great role in maintaining quality of education through various mechanisms. Among these, employing qualified teachers according to their quality and quantity demanded is one element to mention. The local government of the town made its efforts to employ teachers with different educational qualification for the primary schools of the town from the year 2013-2017 that can be seen from Table 4.8.

Table 4.8: Distribution of Newly Employed Teachers in the Primary Schools of the Town

\begin{tabular}{|c|c|c|c|c|c|c|c|c|c|c|c|c|}
\hline \multirow[t]{3}{*}{ Year } & \multicolumn{12}{|c|}{ Level of Qualification } \\
\hline & \multicolumn{2}{|c|}{ TTI } & \multicolumn{4}{|c|}{ Diploma } & \multicolumn{2}{|c|}{ Degree } & \multicolumn{4}{|c|}{ Total } \\
\hline & M & $\mathrm{F}$ & $\mathrm{T}$ & M & $\mathrm{F}$ & $\mathrm{T}$ & M & $\mathrm{F}$ & $\mathrm{T}$ & M & $\mathrm{F}$ & $\mathrm{T}$ \\
\hline 2013 & 2 & 1 & 3 & 4 & 2 & 6 & - & - & - & 6 & 3 & 9 \\
\hline 2014 & 1 & 2 & 3 & 3 & 3 & 6 & - & - & - & 4 & 5 & 9 \\
\hline 2015 & 1 & - & 1 & 5 & 5 & 10 & - & -- & - & 6 & 5 & 11 \\
\hline 2016 & - & - & - & 5 & 7 & 12 & 4 & 1 & 5 & 9 & 8 & 17 \\
\hline 2017 & - & - & - & 6 & 8 & 14 & 2 & - & 2 & 8 & 8 & 16 \\
\hline
\end{tabular}

Source: Gimbi Town Education Office Document, 2018

The numbers of teachers employed in the first two years were constant. Whereas, in the last three consecutive years, it was relatively increasing even if it does not match with the rate at which the number of pupils were increasing. But when we analyze employed teachers in terms of their qualification, there is a slight increment on the side of the number of diploma graduates from year to year. However, there is still a gap between the number of qualified teachers demanded and those employed which helps to cope up with the existing shortage of qualified teachers especially at the second cycle primary schools i.e., (grade 5-8). Moreover, there is a serious problem with regard to the teacher subject distribution. That means there is an accumulated teacher in some subject while there is a shortage in some subject areas like physics and chemistry.

\subsection{Budget of the Education Sector in Gimbi Town}

Education needs different educational facilities to be carried out efficiently and effectively. Among these elements; buildings, equipment, supplies, furniture, books, teachers' salaries etc. are the most common one. Therefore, for 
the adequacy of the mentioned facilities in the schools, allocation of sufficient budget is the necessary requirement. Among the major elements in any given country, it is the method of allocating funds for financing education that determine the extent of access for education, the type of education given, the pattern of student distribution, the level and quality of education, and the overall management and direction of educations (MoE, 2002).

The method of financing education in any given country is among the major elements that determine the extent of access for education, the type of education given, the pattern of student's distribution, the level and quality of education, and the overall management and direction of educations (ibid). Primary education remains the highest priority for the Government of the Federal Democratic Republic of Ethiopia and hence, it receives the highest share from the total expenditure of the country. In connection to this, the budget of the education sector of the town for the last five consecutive years is illustrated as follows.

Figure 4.1: Allocated Budget for the Town Administration, Education Sector, and share of the Primary Schools 2013-2017 in ETB

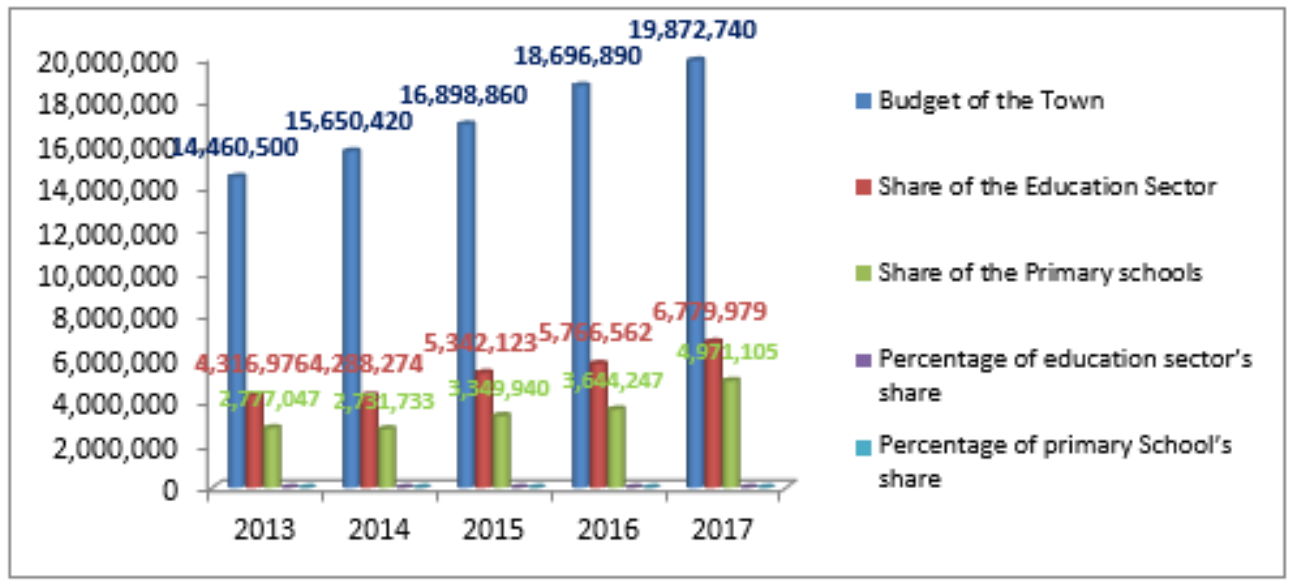

Source: Gimbi Town Finance and Economic Development Office, 2018

The above Figure 4.1 shows the trends of the town administration and education office's budget from the year 2013-2017. As indicated, the share of education sector out of the total budget has been tremendously increased from $29.85 \%$ in 2013 to $34.12 \%$ in 2017 even if the budgets share shown a slight reduction in the year 2014 and 2016. Of this budget, about $60 \%$ went to the primary schools and even more which accounts to $73 \%$ in the year 2011 allocated to the primary schools of the total budget given to the education sector. From this, one can infer that the town has allocated about one third of its budget to education sector and hence the trend of the share of the five year's budget is encouraging even though it does not match with the growing demand of educational facilities and services.

Confessing its inadequacy, the town education office and directors of all the primary schools assured that the above budget not enough to provide educational facilities since this budget includes salary of the teachers, capital and recurrent budget. On the other hand, there is a rapid increment of students' population in the town resulted from rapid population growth which is mainly due to rural-urban migration. This requires the initiation to build new schools, adding new classes in the existing schools and above all providing educational materials.

\subsection{Educational Facilities/ Inputs}

Educational facilities are very important inputs in ensuring the quality of education. They are critical ingredients in teaching-learning activities that speed up the implementation of the intended curriculum goals. These materials and facilities that enhance students' achievement in educational service provision are called furniture and equipment which include the set of special environment, physical structure, space arrangements, text books, teacher's guides, computers, maps and other aids (Marlaine, 1994). In connection to this, what an existing facilities seems in the study area is examined and hence, data obtained proved, the necessary facilities are not adequate in most schools of the town. These materials include: teacher's guide, laboratory, laboratory equipment, water supply, electricity, telephone, access to road, blackboard, toilet, pedagogical center, library, teaching aids and etc. are some of them.

As to Miske and Dowd (1998), the quality of school buildings may be related to other school quality issues, such as the presence of adequate instructional materials and textbooks, working conditions for students and teachers, and the ability of teachers to undertake certain instructional approaches. Such factors as on-site availability of lavatories and a clean water supply, classroom maintenance, space and furniture availability all have an impact on the critical learning factor of time on task. When pupils have to leave school and walk significant distances for clean drinking water, for example, they may not always return to class. In this regard, primary schools' teachers and directors are asked on the adequacy of educational facilities because these respondents have more 
understanding on the issue than other respondents. In line with this, the result of questionnaire administered during the field survey shows that $62.5 \%$ of the sampled teachers assured the inadequacy of teachers guide; $27.4 \%$ of the respondents replied the unavailability of teacher's guide in their schools. It is only $10.2 \%$ of the teacher respondents those replied the adequacy of the teacher's guide in the primary schools.

Regarding the availability of laboratory and laboratory equipment, all the teachers and director respondents assured the absence of these educational facilities in all the primary schools of the town. This indicates the nonexistence of the noteworthy educational facilities which can directly affect the provision of quality education in the primary schools of Gimbi town. Data collected also illustrates the degree of the provision of water supply within the primary schools of the town. In this regard research conducted by Desalegn (2013) shows there is a serious water supply service in the town, which is 6.08 liter per person per day showing its inadequacy. In addition to this, the information obtained from the sample respondents of both teachers and directors, there is a severe problem of water supply service in all the primary schools, where mass $(69.5 \%)$ of the teachers and $(77.78 \%)$ of directors proved the complete absence of the service in the primary schools of Gimbi town. The remaining $30.5 \%$ of the sampled teachers and $22.22 \%$ of the directors replied the shortage of water supply service in the primary schools of the town. This indicates serious problem in the availability of the educational facilities in the primary schools of the town.

It is also possible to investigate the condition of electricity, telephone and road service in the primary schools. These facilities are relatively better as compared to the other facilities which are proved by $64.8,79.7$ and $84.4 \%$ of the sampled teacher respondents respectively and $44.45 \%$ of all the services by the directors of the schools. From this, it is possible to analyze that the existing primary schools have no as such serious problems of electricity, telephone and access road services.

In connection to the existing condition of blackboard in the primary schools of the town, evidence verifies that $28.1 \%$ of the teachers and $55.55 \%$ of the directors confirmed the sufficiency of its provision. On the other hand, taking into consideration its quality, $71.9 \%$ of the sample teachers and $44.45 \%$ of the directors attested its insufficiency. This also indicates there is undeniable problem in the schools as blackboard is one of the important facilities in the teaching-learning process in developing countries like Ethiopia where there is no any alternatives. Toilet is another important facility in the schools' compound. As to the belief of the majorities of the teacher respondents i.e., $81.3 \%$ and $44.45 \%$ of the directors, there is laughable toilet facilities provision in their schools. While $10.2 \%$ of the teachers and $11.11 \%$ of the directors confirmed that toilet facility is absolutely none in their schools. They are only $8.6 \%$ of the sampled teachers and $22.22 \%$ of the directors who replied that there is adequate provision of toilets in the primary schools of Gimbi town. This signifies that there is a problem of toilet facilities in primary schools of the town. This in turn indicates the existence of sanitary problems in the primary schools of the town, which affects the health condition of the students. This might be a reason for students' school dropout and repetition.

The other decisive facilities in educational service provision are the existence of pedagogical center, library, and teaching aids that have their own roles in maintaining the delivery of quality education. On these educational inputs, the field survey result is enlightened as follows. As far as the pedagogical center is concerned, $83.6 \%$ of the teachers and $44.45 \%$ of the directors highlighted that the service is seriously scarce in the primary schools of the town. There are also $3.9 \%$ of the sampled teachers who assured the absence pedagogical centers in their schools. Contrary to this, $12.5 \%$ of the primary schools' teacher respondents and $33.33 \%$ of the directors responded that there is adequate provision of pedagogical centers in the primary schools of the town. This shows in the majority of the primary schools, there is inadequate provision of pedagogical centers.

As far as the provision of library is concerned, still the sampled teachers of the primary schools and director respondents are asked whether it is adequate. Hence, the majority, $59.4 \%$ of the teacher respondents and $44.45 \%$ of the directors witnessed that there is not as much as necessary provision of library service in their schools. While $34.3 \%$ of the teachers and $33.33 \%$ of the directors confirmed that library service is not accessible in their schools. Focusing on the majorities' response, there is no sufficient library service in the primary schools of the study area.

With regard to the provision of teaching aids, majority of respondents i.e., $62.5 \%$ of the sample teachers and $33.33 \%$ of the directors responded that its provision is inadequate in the schools. On the other hand, $37.5 \%$ of the sampled teachers and $44.45 \%$ of the directors responded that there is adequate provision of the service in their schools. Contrary to this, $22.22 \%$ of the directors proved its absence in the primary schools of the town. In general, one can infer that of the necessary educational facilities except blackboard, electricity, telephone, road, all the aforementioned show scarcity, which can directly affect the quality of educational service delivery. On the same issue an interviewed supervisors confirmed that there is a severe shortage of educational materials in all the primary schools of the town. They also replied that teachers are repeatedly raising the question of the availability of educational materials and they are also reporting regularly to the town education office though it is not solved yet. 

4.8.1 The Primary Schools' Directors Response on the Degree of Warehouse, Sewerage and Clinics in the
Primary Schools of the Town

Figure 4.2: Directors' Response on the Degree of Warehouse, Sewerage and Clinics

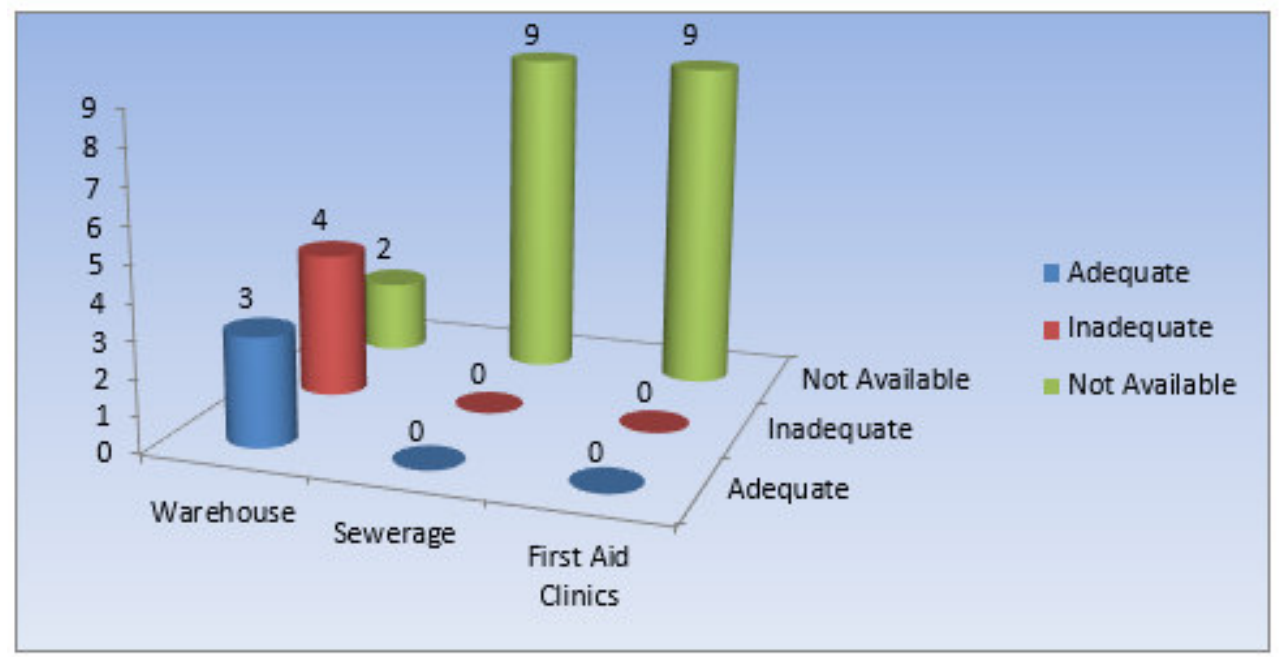

Source: Field Survey, 2018

With regard to the availability of warehouse, sewerage and first aid clinics, the interviewed directors expressed their opinion as the following. Consequently, $3(33.33 \%)$ of the primary schools' directors reacted that warehouse is plentywhile4 $(44.45 \%)$ of them confirmed its scantiness in their schools and the rest proved its absence in their schools. From this, one can generalize that there is a problem of warehouses in the existing primary schools of the town. Concerning the accessibility of sewerage and clinic services in the primary schools of the town, all of them confirmed about the deficiency of sewerage services and first aid clinics in their schools. From this, one can generalize that almost all the primary schools lack the necessary facilities which in turn affects the provision of quality education in the town (Figure 4.2).

4.8.2 Primary Schools' Teachers Respondents on the Adequacy of Stationeries, Sport Materials, and Chalk in their Schools

Figure 4.3: Teachers' Response on the Provision of Stationeries, Sport Materials and Chalks

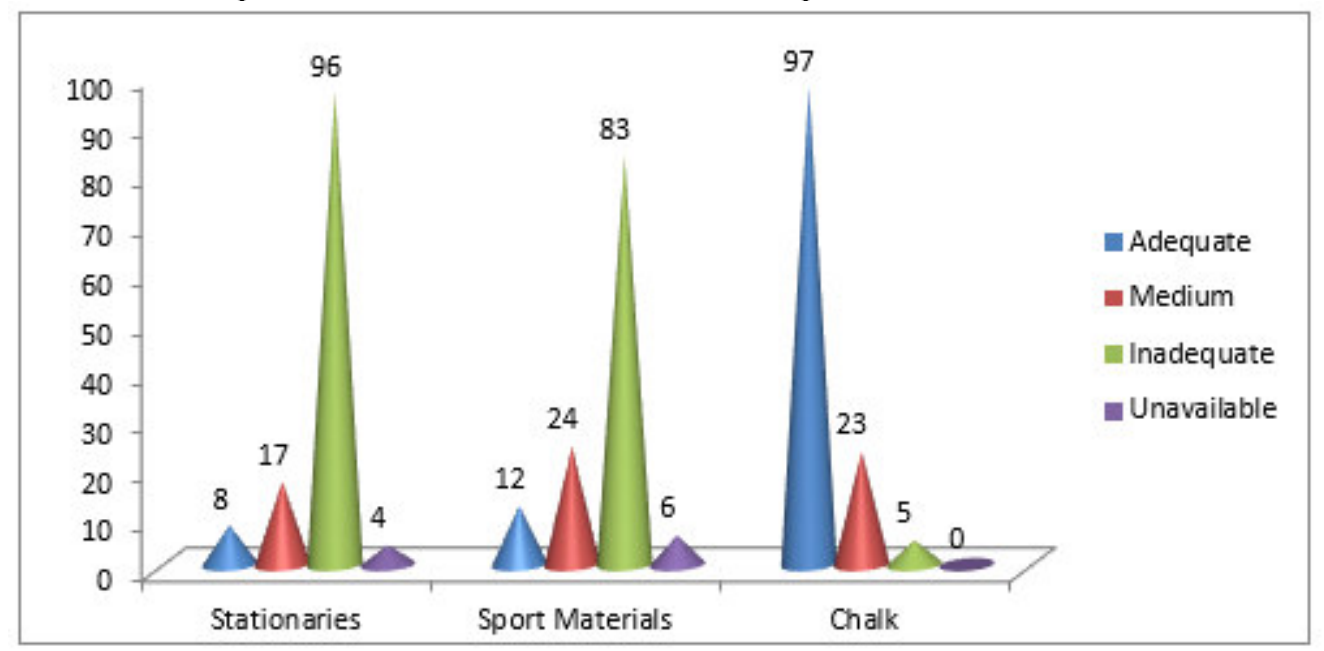

Source: Field Survey, 2018

As clearly seen from Figure 4.3 , the majority $(96,76.8 \%$ ) of the sampled respondents confirmed the inadequacy of stationery materials showing that many schools suffer from the shortage of stationeries. The same is true with the provision of sport materials where $83(66.4 \%)$ of the respondents claimed an inadequate quantities of the noted materials in the primary schools of the town. On the other hand, $6(4.8 \%)$ of the teachers' respondents confirmed the unavailability of the sport materials in their schools. From this, it is possible to deduce that the provision of the listed facilities is not at the required standard in the schools where even some of these are completely absent in the primary schools of the town. It is only chalk, which seems to be adequate the reply of the majority $97(77.6 \%)$ confirmed. This verifies most of the educational materials are not in a position to facilitate the provision of quality education in the study area. 


\subsection{Causes of Inadequate Provision of Educational Services and Facilities in Gimbi Town}

As Figure 4.4 and Figure 4.5 below shows the primary schools' teachers and schools' PTA/ETMB respondents considered rural-urban migration which increased students' population in the schools, low level of stakeholder participation, insufficient budget and educational materials as a cause of inadequate provision of educational service and facilities in the town.

Figure 4.4: Teacher Respondents on the Causes of Inadequate Provision of Educational Service and Facilities in the Town.

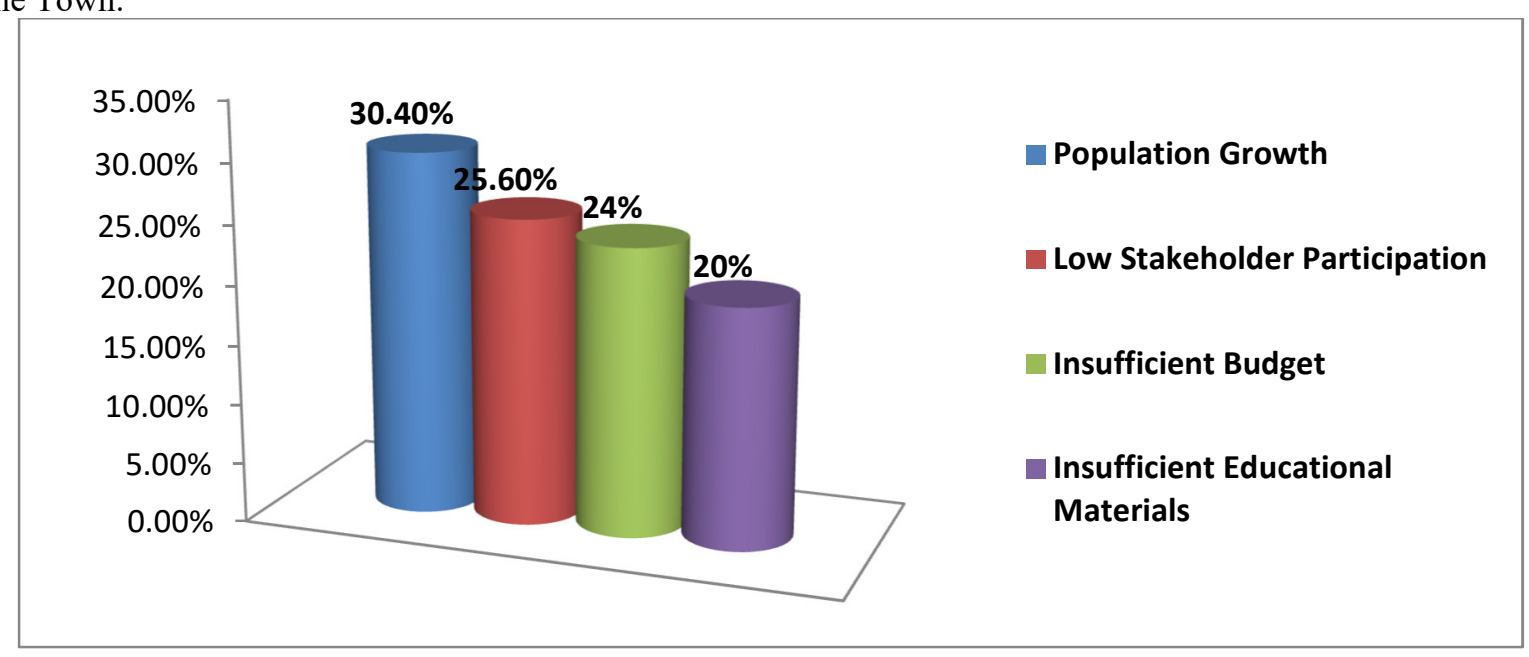

Source: Field Survey, 2018

Figure 4.5: Reply of PTA/ETMB Respondents on the Causes of Inadequate Provision of Educational Service and Facilities in the Town

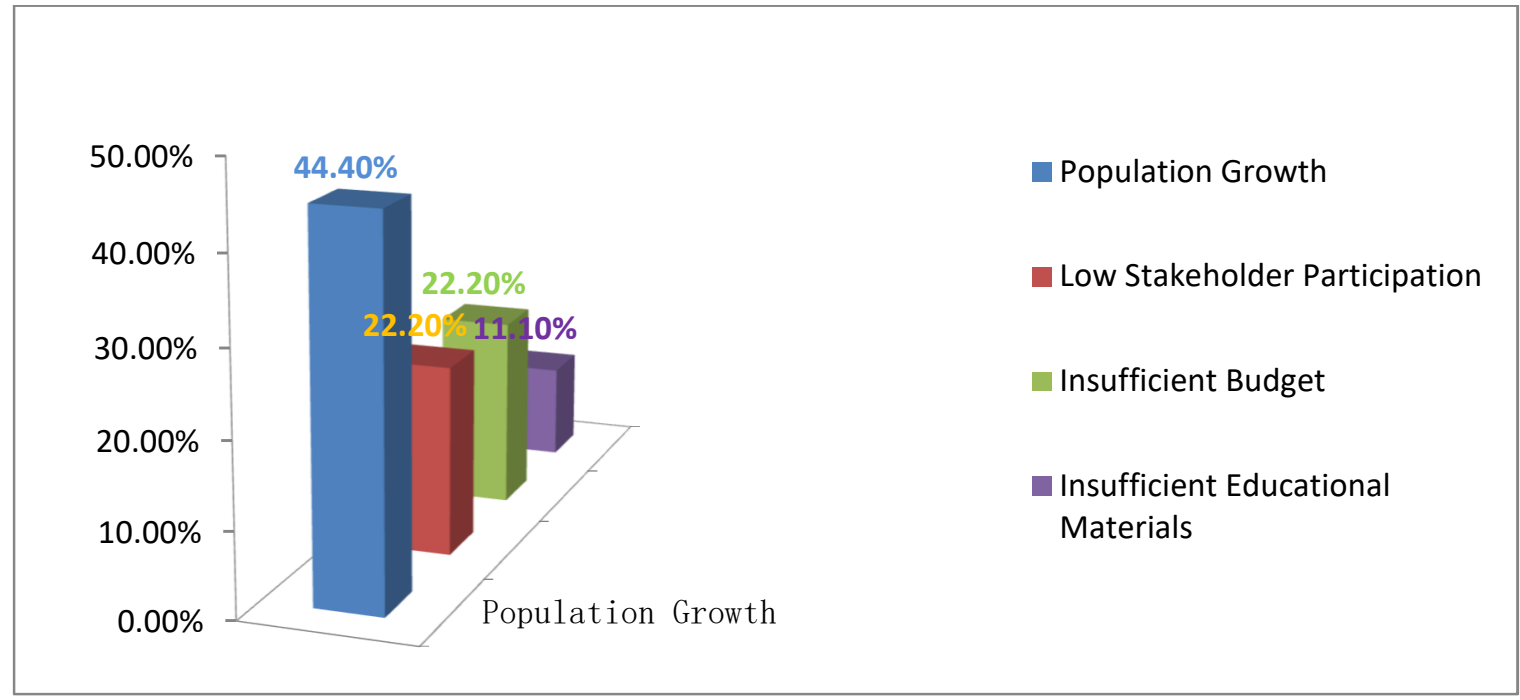

Source: Field Survey, 2018

From the view point of the sample primary schools' teachers respondents, the cause of inadequate educational service provision in the primary schools is population growth, low involvement of stakeholders, insufficient budget and educational materials respectively as replied by 38 (30.4\%), 32 (25.6\%), 30 (24\%) and $25(20 \%)$. Concerning the feeling of schools' PTA/ kebele ETMB members, the same Figure indicated that 4 (44 \%), 2 (22\%), $2(22 \%)$ and $1(11 \%)$ of the respondents respectively said that population growth, insufficient budget, low level of stakeholders participation and insufficient educational materials are some the reasons listed by the respondents involved in the field survey. From this, one can say that population growth is a serious challenge for the shortage of provision of educational services and facilities in town's primary schools as confirmed from both the teacher respondents' and PTA/ kebele ETMB members.

\subsection{Manpower of the Town Education Sector}

In addition to the educational materials and different equipment, an existing human resource is the other factor, which determines the effectiveness and efficiency of an organization. Currently, Gimbi town education office has 
22 permanent employees. These workers have the necessary educational background and enough experience in the field. In spite of this, when compared with the activities expected of them, they are not sufficient since they have to organize and manage all educational level in the town i.e. about four pre-primary schools (KG), nine primary schools, two high schools (9-10) and one preparatory school. This signifies manpower of the town education sector is not adequate to carry out the necessary activities expected from the education sector. They are anticipated to fill the existing skill gaps by preparing different trainings, monitor, evaluate and take the necessary measures to improve quality education to be delivered. Nevertheless, they are not in a position to perform what school environment expects from them.

The town has weak institutional capacity to provide basic social services like education. Moreover, low stakeholders' participation and rapid population growth which is mainly resulted from rural-urban migration limited the provision of adequate educational services and facilities. In addition to inadequacy of educational facilities in the town, the physical conditions of an existing facility reveal that buildings are dilapidated and deteriorated, class rooms not maintained for years, students share furniture, rooms and books beyond the standard set by the Ministry of education. In short, shortage of schools, classrooms, instructional materials, teaching aids, inadequate trained teachers and officials, and inadequate budget limited access and the coverage of the primary schools in the town.

Therefore, in order that the educational sector meets its vision and mission, weight should be given to the above problems that can be a threat to the achievement of the country's educational sector.

\section{Summary of Findings, Conclusion and Recommendations 5.1 Summary of Findings and Conclusion}

On the basis of the data gathered during field survey and analysis made, the following major findings were identified which are stated in line with the stated objectives of the study: An existing conditions and major factors affecting the provision of quality educational services and facilities in the town are:

\section{Low Stakeholders' Participation}

As it is reveled in the analysis part, $88.89 \%$ of the primary schools are owned by the government and only $11.11 \%$ of them are owned by Religious Based Organization in the town. There is no privately owned primary school. This indicates the local government is expected to encourage the private, NGOs and Community in order them participate in the investment of the education sector to satisfy the growing demand of education in the town.

\section{Rapid Population Growth leading to Rapid Urbanization}

Currently, as other urban areas, there is high rate of population growth in Gimbi town which its growth is accelerated by instantaneous in migration process. Contrary to this, the urban local government is not in a position to provide the physical infrastructure or facilities and socio-economic services since it is characterized by urbanization without growth. This implies fast urbanization puts enormous demand on the government to create educational opportunities.

As observed from the finding i.e. (Fig 4.4 and 4.5), 39 (30.4\%) of the primary school teacher respondents and 7 ( $35 \%$ ) of the PTA/ kebele ETMB member respondents reacted that population growth, which is the result of ruralurban migration caused inadequate provision of educational services and facilities in the town. Likewise, school age population from the year 2013 to 2017 is increasing. This signifies population growth due to either natural growth or migration an existing scenario in the town.

\section{Inadequacy of Educational Materials and Facilities}

The availability and adequacy of educational facilities in the school determines the quality of educational services provided. In this regard, the town administration and education office provide some of the required facilities in the primary schools of the town. However, some of the schools' facilities such as toilet, water supply, and student's textbook and so on are inadequately provided. Whereas facilities such as first aid clinic, sewerage, laboratory and laboratory equipment are absolutely absent in the primary schools of Gimbi town. In addition to this, there is lack of teaching aids that can create child friendly school environment. All these imply that there is poor situation of an existing educational services and facilities in the town.

The existing school to pupil ratio, section to pupil ratio and teacher to pupil ratio are also revealed. Accordingly, the existing school to pupil ratio and section to pupil ratio are far below the national standard set. For instance, as to the standard, school to pupil ratio at the primary level allows 1:1600 but as seen from the last five consecutive years (2013 to 2017), all of the sampled primary schools of the town are serving beyond this. With regard to section to pupil ratio, the standard set at the primary schools is 1:50. However, the existing ratio on average is about 1:76, which is exceeding the standard set by 26 students in each classes and even by far above this in some primary schools. This has a leading role for the schools to carry out a teaching-learning process by shifting that is, by half time to accommodate more students. As far as the trends of dropout and repetition are concerned, for the last five consecutive years, together account about 7,554. When we compare the two sexes, it was high among the females, which accounts to 4,099, verifying gender disparity in the town primary schools. 


\section{Low Institutional Capacity and Performance}

The town education sector does not have appropriate quality and quantity of human resources. The one who leads the other should be better of the one who is to be led, but in case of the concerned institution there is a gap which affects its performance. Moreover, there is lack of qualified manpower particularly qualified teachers at the second cycle primary education. Assigning under qualified human resources is also another problem of the town. In short, lack of adequate qualified manpower is identified as the major challenges to the provision of educational services and facilities in the town.

\section{Lack of Adequate Financial Resources}

Schools can generate resources from income-generating activities, through government, families, the community and non-governmental organizations. Schools may also benefit from resources (cash, in kind or in labor) used for activities and inputs. From the results of the study, it is possible to understand that the amount of budget allocated by the government for the education sector is not sufficient. Besides, other parties are not contributing their role and also schools themselves are not actively working to generate their own income. Thus, lack of adequate financial resource is adversely affecting the educational systems from improving access, quality, equity and efficiency of education system. This in turn could hinder the local government to employ qualified human resources, to construct the required classrooms, and to provide all educational facilities.

\section{Lack of Motivation}

As to the view of psychologists, motivation plays a great role while accomplishing some activities. Research conducted in such areas show variation between and among those people who got incentive and those who did not. It is obvious that in schools, motivation has a direct role in performing better activities. In line to this, the interview shows there is no any type of motivation.

In conclusion, from the study, it is possible to understand that there is a beginning to improve the access, quality, equity, and efficiency of education system of the town. Nevertheless, there is still low institutional capacity and performance, low stakeholders participation, lack of institutional integration, lack of skilled manpower, dilapidated buildings, inadequacy of educational facilities and above all there is lack of financial resources to adequately provide the necessary educational services and facilities in the town.

\subsection{Recommendations}

The data analysis, findings and conclusions in the proceeding sections provide some insights about the existing situations. They also provide the ground to suggest some recommendations to take measures that could be a springboard to solve the existing problems in the primary schools of the town. Based on the findings obtained and conclusions drawn, possible suggestions include: encouraging Stakeholders' Participation, creating awareness on community participation, constructing additional schools and classrooms, employing adequate qualified manpower, providing schools' facilities, allocating adequate financial resources, improving access and the quality of education, rewarding teachers, directors, supervisors and schools, narrowing the gender disparity, carrying out regular and sustainable maintenance, providing ongoing professional development and implementing effective school rules and regulations are some of the measures to be taken to mitigate factors affecting the provision of adequate educational services and facilities in the town primary schools.

\section{References}

Aggrawal, J., C. (2004). Teacher and Education in Developing Society: Vikas Publishing House PVLTD, New Delhi, India: 290.

Creswell, John, W. (2006). Qualitative, Quantitative and Mixed Methods Approach, Second Edition, Saga Publication.

Derebssa Dufera (2001). Factors Affecting the Implication of Current Curriculum in Ethiopian Primary Schools: In Proceedings of National Conference on Quality of Primary Education in Ethiopia (pp72-91): Addis Ababa University, Adama- Ras Hotel, Ethiopia.

(2008). Quality of Teaching and Learning in Ethiopian Primary School: Tension between Traditional and Innovative Teaching: AAU, Addis Ababa, Ethiopia.

Dereje H/Michael (2008). Analysis of Provision and Management of Education Infrastructure and Service in Holeta Town, Addis Ababa University, Ethiopia.

Desalegn Fekadu (2012). Assessment of Water Supply Infrastructure and Service Delivery in Gimbi Town (Oromia Region), $1^{\text {st }}$ ed. MA. Thesis, Ethiopian Civil Service University: Lap Lambert Publishing, Germany: 1,2 and 7.

(2013). Factors Affecting the Delivery of Quality Educational Services and Facilities in Ethiopia, the Case of Primary Schools (Oromia Regional State): Lap Lambert Academic Publishing, ISBN: 978-3-65940910-3

Fullan, M. (1991). The New Meaning of Education Change: Teachers College Press, Columbia University, New York, USA. 
Hallok, J. (1990). Investing in the future, Setting Education Priority in the Developing World (Executive Summary): UNESCO, Paris, France.

Jeilu Oumer (2007). The Challenges of Free Primary Education in Ethiopia: International Institute for Educational Planning, UNESCO, Addis Ababa University.

Marlaine, E. Lock heed (1994). Improving Primary Education in Developing Countries: Oxford University Press, World Bank, Washington D.C, USA.

Ministry of Education (1994). Ethiopian Education and Training Policy, FDRE, Education and Training Policy: MoE, Addis Ababa, Ethiopia: 1, 15, 16.

(2002). The Education and Training Policy and Its Implementation: Ministry Of Education, Addis Ababa.

(2004). Education Statistics Annual Abstract 2004/05: Ministry of Education, Addis Ababa, Ethiopia.

(2005). Education Sector Development Program III (ESDP III): MoE, Addis Ababa, Ethiopia.

Ministry of Urban Works \& Development (MUWD) (2006). Industry and Urban Development Package (Unpublished). Addis Ababa, Ethiopia.

Miske, S., \& Dowd, A. (1998). Teaching and Learning in Mango chi Classrooms: Combining Quantitative and Qualitative Information to Study Twelve Primary Schools in Malawi. Evaluation Study Conducted for the United States Agency for International Development by Creative Associates International, Washington, D.C.

Polit, D., F. \& Beck, C., T. (2008). Nursing research: generating and assessing evidence for nursing practice. $8^{\text {th }}$ edition. London: Lippincott Williams \& Wilkins.

Pope, D. (1993). The Objectives Model of Curriculum Planning and Evaluation: Occasional Paper 10: Council for Educational Technology for the U.K., London.

SEIA (2007). At the Crossroads: Choices for Secondary Education in Sub-Saharan Africa. Washington D.C, the World Bank

Todaro, M. (1985). Economic Development in the Third World Countries. New York, USA.

UNDP (2003). Human Development Report 2003: A Compact among Nations to and Human Poverty: Oxford University Press, New York, USA.

UNESCO (2000). Regional overview on sub-Saharan Africa: UNESCO, Geneva, Switzerland. (2006). Principal and General Objective of Education: International Bureau of Education.

UNICEF (2000). Determining Quality in Education: Educational Journal, 6(13), 87-121.

World Bank (1993). Education in Sub-Saharan Africa: Policies for Adjustment, Revitalization and Expansion, Washington D.C, USA: 10, 11.

(2004). Education in Ethiopia: Strengthening the Foundation for Sustainable Progress. Human Development Department: the World Bank, Washington D.C, USA.

(2005). Ethiopia Wellbeing and Poverty in Ethiopia: Poverty Reduction and Economic Management: Country Department for Ethiopia-African Region, Washington D.C, USA.

(2006). From Schooling Access to Learning Outcomes, an Unfinished Agenda: An Evaluation of World Bank Support to Primary Education, Washington D.C, USA.

Yamane, Taro (1967). Determining Sample Size, Florida Cooperative Extension Service, University of Florida. 